\title{
Shigella and enteroinvasive Escherichia coli strains are derived from distinct ancestral strains of $E$. coli
}

\author{
Karine Rolland, ${ }^{1}$ Nicole Lambert-Zechovsky, ${ }^{2}$ Bertrand Picard ${ }^{1}$ \\ and Erick Denamur ${ }^{3}$
}

Author for correspondence: Bertrand Picard. Tel: +332980164 56. Fax: +33298016474. Bertrand.Picard@univ-Brest.fr

1 Laboratoire de

Microbiologie, Faculté de Médecine de Brest, 22

Avenue Camille

Desmoulins, B.P. 815 ,

29285 Brest Cedex, France

2 Laboratoire de

Microbiologie, Hôpital

Beaujon, Clichy, France

3 INSERM U 458, Hôpital

Robert Debré, Paris, France

\begin{abstract}
The differentiation between Shigella subspecies, and the phylogenetic position of Shigella clones within Escherichia coli clones was determined by analysis of restriction fragment length polymorphisms of rDNA (ribotyping). Seventy-five Shigella strains belonging to the four subspecies and 13 enteroinvasive $E$. coli (EIEC) strains were compared with the 72 E. coli strains of the ECOR collection, which have been classified into four phylogenetic groups (A, B1, B2 and D). Seventeen Shigella dysenteriae ribotypes, 12 Shigella flexneri ribotypes, 23 Shigella boydii ribotypes, 12 Shigella sonnei ribotypes and 13 EIEC ribotypes were identified following digestion with HindIII and EcoRI. Correspondence analysis of the data showed that $S$. boydii serotype 13 strains were distantly related to the other Shigella strains, and that S. sonnei and S. flexneri were distinct from S. boydii and S. dysenteriae. The ribotypes of Shigella and ECOR strains were indistinguishable, and S. sonnei, $S$. flexneri and most $S$. dysenteriae strains were closely related to phylogenetic group $D$, whereas $S$. dysenteriae serotype 1 strains belonged to phylogenetic group B1, and S. boydii strains were evenly distributed between the two groups. The Shigella strains were distantly related to group B2, which contains $E$. coli strains frequently implicated in extra-intestinal infections in humans. In contrast, the 13 EIEC strains were more widely distributed between phylogenetic groups B1, $A$ and B2. Thus, there was no primordial Shigella species and Shigella and EIEC strains are derived from different ancestral strains.
\end{abstract}

Keywords: Shigella, Escherichia coli, enteroinvasive Escherichia coli (EIEC), phylogeny

\section{INTRODUCTION}

DNA hybridization studies have shown that Shigella (with the exception of Shigella boydii serotype 13) and Escherichia coli belong to the same genetic species (Brenner et al., 1972, 1973, 1982). However, nutritional characterization, numerical taxonomy and enzyme electrophoresis show that there are differences between these organisms (Johnson et al., 1975; Veron \& Le Minor, 1975; Ochman et al., 1983) and within Shigella, between the four taxospecies, Shigella dysenteriae, Shigella flexneri, S. boydii and Shigella sonnei (Goullet 1980; Dodd \& Jones, 1982). A previous analysis of

Abbreviations: EIEC, enteroinvasive Escherichia coli; MLEE, multilocus enzyme electrophoresis; RAPD, random amplified polymorphic DNA; RFLP, restriction fragment length polymorphism. esterase electrophoretic polymorphisms distinguished five clusters among the Shigella: (1) $S$. dysenteriae serotype 1 ; (2) S. flexneri serotypes 1-5; (3) S. flexneri serotype 6 and $S$. boydii serotypes 2 and 4 ; (4) S. sonnei; and (5) S. boydii serotype 13. These clusters are more closely related to $E$. coli than to each other (Goullet \& Picard, 1987).

The concept of a clonal structure was developed by Selander \& Levin (1980) for E. coli and subsequent studies have shown that the linkage disequilibrium in this species is very close to the theoretical maximum, indicating that recombination events are rare. Moreover, the clonal structure of the species was demonstrated by the similarity obtained within the ECOR collection of $72 \mathrm{E}$. coli strains for phylogenetic trees based on three kinds of data (Ochman \& Selander, 1984; Desjardins et al., 1995).The four phylogenetic 
groups A, B1, B2 and D, described by Herzer et al. (1990) on the basis of multilocus enzyme electrophoresis (MLEE), are also distinguishable by random amplified polymorphic DNA (RAPD), and restriction fragment length polymorphism (RFLP) analysis of rDNA genes (ribotyping). Thus ribotyping can be useful for classification of the E. coli and Shigella clones.

We first investigated the differentiation between the Shigella clusters by rDNA gene RFLP analysis of Shigella strains belonging to the four taxospecies. We then determined the phylogenetic position of the Shigella clones and of a group of enteroinvasive E. coli (EIEC) strains within the ECOR collection. This allowed us to assign the Shigella and EIEC strains to the previously described E. coli phylogenetic groups A, B1, B2 and D (Herzer et al., 1990).

\section{METHODS}

\section{Bacterial strains}

Shigella strains. The strains tested are listed in Table 1. We used $22 S$. dysenteriae strains, 13 S. flexneri strains, 24 S. boydii strains (including two serotype 13 strains) and $16 \mathrm{~S}$. sonnei strains.

E. coli strains. The 72 ECOR strains were obtained from R. K. Selander, Pennsylvania State University, USA and the 13 EIEC strains were obtained from Dr P. Bouvet, Institut Pasteur, France (strains CNRSS 84-293, 85-90, 85-200, 85-206, 85-209, 85-242, 85-255, 94-8778, 95-7511 and 95-11794) and Dr Sansonetti, Institut Pasteur, France (strains 4608-0124, 1-72 and 13-80). The EIEC were shown to be enteroinvasive by the Sereny test (Sereny, 1955) for three strains or by hybridization using DNA probes (Bohnert et al., 1988) for the others. Among the EIEC, two were motile.

RFLP of rDNA regions. Bacterial DNA was prepared as previously described (Picard-Pasquier et al., 1989). DNA was digested with EcoRI and HindIII restriction endonucleases (Boehringer) according to the manufacturer's instructions and was analysed by electrophoresis on submerged $0.8 \%$ agarose gels containing ethidium bromide. DNA fragment size markers (marker II; Boehringer) were used. Separated DNA restriction fragments were transferred to a nylon membrane (Amersham) by Southern blotting (Southern, 1975). Ribosomal 16S and 23S RNA from E. coli (Boerhinger) was labelled by random oligopriming using a chemiluminescence system (Boehringer) as previously described (Bingen et al., 1992). Hybridization, washing and detection procedures were as previously described (Bingen et al., 1992)

Statistical analysis. The data were summarized in two twoway tables containing 72 rows for the 72 ECOR strains and 88 rows for the 75 Shigella strains and the 13 EIEC strains. The number of columns corresponded to the number of rDNA fragments produced by EcoRI and HindIII endonuclease digestion. For each column, the rDNA fragment was coded using a binary code, present $=2$ or absent $=1$, for each strain.

Correspondence analysis (Greenacre, 1984; Lebart et al., 1984; Tenehaus \& Young, 1985) was performed for Shigella strains using one table. The other table was used for correspondence analysis of ECOR strains, in which the strains of Shigella and EIEC were treated as supplementary observations and were projected onto the factorial plane F1/F2 (see
Fig. 3) obtained from the ECOR strains. Calculations were carried out using SPAD.N software.

\section{RESULTS}

\section{RFLP analysis of rDNA regions}

S. dysenteriae. rDNA was digested with EcoRI and 20 rDNA fragments $2-24 \mathrm{~kb}$ in size (Fig. 1a) were obtained from the 22 strains. We distinguished 17 rDNA RFLP patterns. When rDNA was digested with HindIII, fragments of 1.9-23.1 kb (Fig. 1b) were obtained and 10 rDNA RFLP patterns were identified. A combination of patterns resulting from both digestions was used to define ribotypes. Seventeen ribotypes were identified among the strains.

S. flexneri. EcoRI digestion produced 19 rDNA fragments $2-24 \mathrm{~kb}$ in size (Fig. 1a). There were $12 \mathrm{rDNA}$ RFLP patterns in the 13 strains. HindIII digestion produced 18 rDNA fragments $1 \cdot 9-23.1 \mathrm{~kb}$ in size which distinguished nine rDNA RFLP patterns (Fig. 1b). Twelve ribotypes were identified among the strains.

S. boydii. EcoRI digestion gave 23 rDNA fragments $2-24 \mathrm{~kb}$ in size (Fig. 1a), which distinguished $22 \mathrm{rDNA}$ RFLP patterns among the 24 strains. HindIII digestion gave 21 rDNA fragments $1.9-23.1 \mathrm{~kb}$ in size (Fig. 1b), which distinguished 16 rDNA RFLP patterns. Twentythree ribotypes were identified among the strains.

S. sonnei. EcoRI digestion produced 19 rDNA fragments with sizes of 2-24 kb (Fig. 1a), distinguishing 11 rDNA RFLP patterns. HindIII digestion produced $12 \mathrm{rDNA}$ fragments $1 \cdot 2-23 \cdot 1 \mathrm{~kb}$ in size (Fig. 1b), which distinguished three rDNA RFLP patterns. Twelve ribotypes were identified among the strains.

EIEC. EcoRI digestion produced 16 rDNA fragments with sizes of $2-24 \mathrm{~kb}$. Thirteen rDNA RFLP patterns were distinguished. HindIII digestion gave eight rDNA fragments of $1 \cdot 9-23.1 \mathrm{~kb}$ in size, which distinguished nine rDNA RFLP patterns. Thirteen ribotypes were identified among the 13 strains.

\section{Statistical analysis}

Correspondence analysis was carried out with the ribotyping data obtained by the combination of the two endonucleases for the 75 Shigella strains. The plane $\mathrm{F} 1 / \mathrm{F} 2$, which accounted for $25.5 \%$ of the total variance, showed that $S$. sonnei and S. flexneri strains were clearly distinguished from $S$. boydii (except serotype 13) and $S$. dysenteriae strains by the negative values of the first axis (Fig. 2). The second axis differentiated S. sonnei strains from $S$. flexneri strains, and $S$. boydii strains from $S$. dysenteriae strains. $S$. boydii serotype 13 strains were clearly distinguished from the other Shigella strains by the negative values of the first axis and the positive values of the second axis.

Correspondence analysis was carried out with the ribotyping data obtained by combination of the two endonucleases for the 72 ECOR strains and the plane 
Table 1. Strains of Shigella examined

\begin{tabular}{|c|c|c|c|c|c|}
\hline \multicolumn{6}{|c|}{ S. dysenteriae } \\
\hline & Strain no. & Serotype & & Strain no. & Serotype \\
\hline D1 & 8.76 & 3 & D12 & 67.81 & 2 \\
\hline D2 & 15.77 & 1 & D13 & 85.99 & 2 \\
\hline D3 & 53.1 & 2 & D14 & 93.46 & 7 \\
\hline D4 & 30.73 & 5 & D15 & 93.45 & 4 \\
\hline D5 & 2.64 & 2 & D16 & 93.51 & 10 \\
\hline D6 & 5.77 & 2 & D17 & 52.27 & 1 \\
\hline D7 & 31.73 & 7 & D18 & 53.136 & 1 \\
\hline D8 & 12.77 & 1 & D19 & 54.95 & 1 \\
\hline D9 & 3.76 & 2 & D20 & 55.90 & 1 \\
\hline D10 & 6.77 & 4 & D21 & 56.33 & 1 \\
\hline D11 & 48.37 & 5 & D22 & 62.17 & 1 \\
\hline \multicolumn{6}{|c|}{ S. flexneri } \\
\hline & Strain no. & Serotype & & Strain no. & Serotype \\
\hline F1 & 10.80 & 6 & F8 & $82.48 \mathrm{~T}$ & $2 a$ \\
\hline F2 & 14.79 & 6 & F9 & 52.24 & 4 \\
\hline F3 & 18.70 & 2 & F10 & 52.36 & $1 \mathrm{a}$ \\
\hline $\mathrm{F} 4$ & 6.74 & 6 & F11 & 52.39 & $2 \mathrm{~b}$ \\
\hline F5 & 66.79 & 4 & F12 & 52.40 & 3 \\
\hline $\mathrm{F} 6$ & 302.78 & 6 & F13 & 52.44 & 5 \\
\hline F7 & 3.77 & 6 & & & \\
\hline \multicolumn{6}{|c|}{ S. boydii } \\
\hline & Strain no. & Serotype & & Strain no. & Serotype \\
\hline B1 & 52.23 & 1 & B13 & E. 20 & 2 \\
\hline B2 & 42.80 & 1 & B14 & E. 24 & 5 \\
\hline B3 & 41.80 & 11 & B15 & E. 25 & 9 \\
\hline B4 & 12.80 & 10 & B16 & E.33 & 9 \\
\hline B5 & 19.80 & 5 & B17 & E.35 & 1 \\
\hline B6 & 54.73 & 1 & B18 & E.36 & 5 \\
\hline B7 & 56.36 & 5 & B19 & 93.21 & 11 \\
\hline B8 & 12.77 & 10 & B20 & 85.92 & 14 \\
\hline B9 & 2.77 & 9 & B21 & 5.16 & 11 \\
\hline B10 & 16.76 & 2 & B22 & 56.18 & 11 \\
\hline B11 & 57.43 & 9 & B23 & 76.114 & 13 \\
\hline B12 & 5.99 & 10 & B24 & 76.115 & 13 \\
\hline \multicolumn{6}{|c|}{ S. sonnei } \\
\hline & Strain no. & Biotype $^{*}$ & & Strain no. & Biotype \\
\hline S1 & 217.77 & a & S9 & 13.77 & $a$ \\
\hline S2 & 2.77 & a & $\mathrm{S} 10$ & 1.78 & $\mathrm{~g}$ \\
\hline S3 & 110.77 & a & S11 & $82.49 \mathrm{~T}$ & g \\
\hline S4 & 4.76 & $\mathrm{~d}$ & $\mathrm{~S} 12$ & 51.1 & $\mathrm{~g}$ \\
\hline S5 & 46.70 & $\mathrm{a}$ & $\mathrm{S} 13$ & 52.55 & d \\
\hline S6 & 5.75 & d & S14 & 55.56 & d \\
\hline S7 & 241.77 & d & S15 & 66.4 & a \\
\hline S8 & 15.77 & d & S16 & 67.63 & a \\
\hline
\end{tabular}

*Biotypes were defined according to Szturm-Rubinstein (1964). (a)

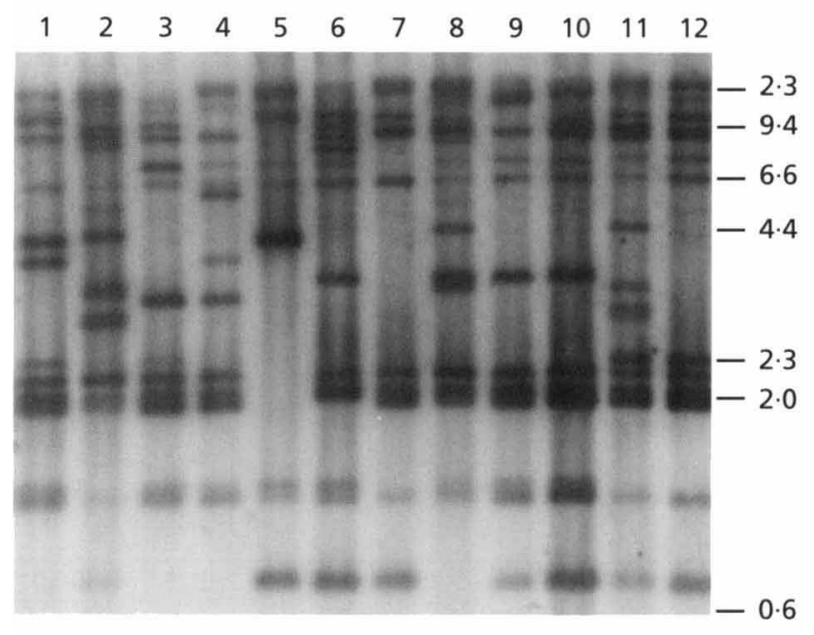

(b)

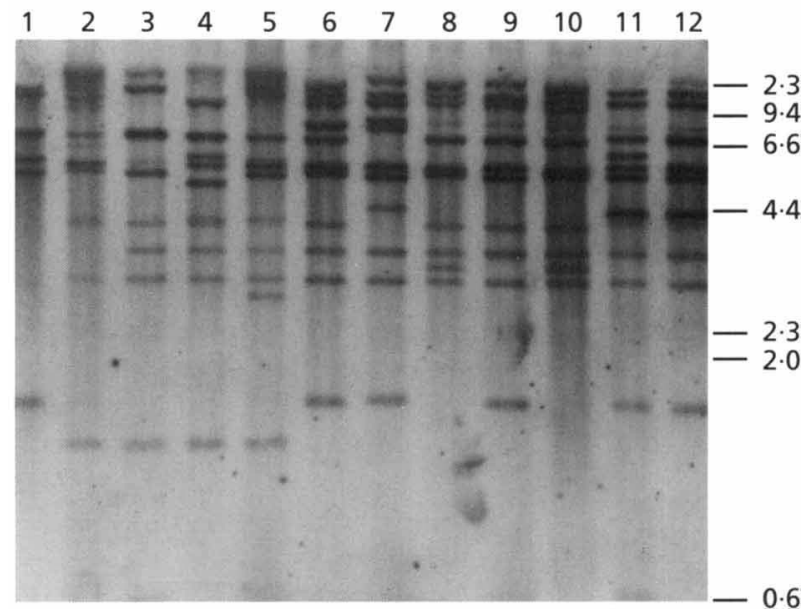

Fig. 1. Representative RFLP patterns of Shigella and ECOR rDNA regions obtained with (a) Hindlll and (b) EcoRI digestion enzymes. Lanes: 1, strain ECOR (E) $1 ; 2$, strain E29; 3, strain E50; 4 , strain E63; 5, Shigella strain D2; 6, strain D10; 7, strain F3; 8 , strain $\mathrm{F} 5 ; 9$, strain B6; 10 , strain B10; 11, strain $\mathrm{S} 5 ; 12$, strain 88 . The strains are numbered as in Table 1 . Positions of size markers are indicated on the right in $\mathrm{kb}$.

F1/F2 was obtained (Fig. 3). The 75 Shigella strains and the 13 EIEC strains, treated as supplementary observations, were projected onto this plane, which accounted for $34.85 \%$ of the total variance. The majority of the ECOR strains were classified within the four phylogenetic groups A, B1, B2 and D previously distinguished by Herzer et al. (1990) using MLEE and by Desjardins $e t$ al. (1995) using ribotyping and RAPD analysis. The Shigella strains were projected into the same area as the ECOR strains. This shows that their ribotypes are very close to those of E. coli strains. However, no Shigella strains were projected within the area of phylogenetic groups A and B2, and all Shigella strains were projected within the area of phylogenetic groups B1 and D. Seven of the eight $S$. dysenteriae serotype 1 strains were 


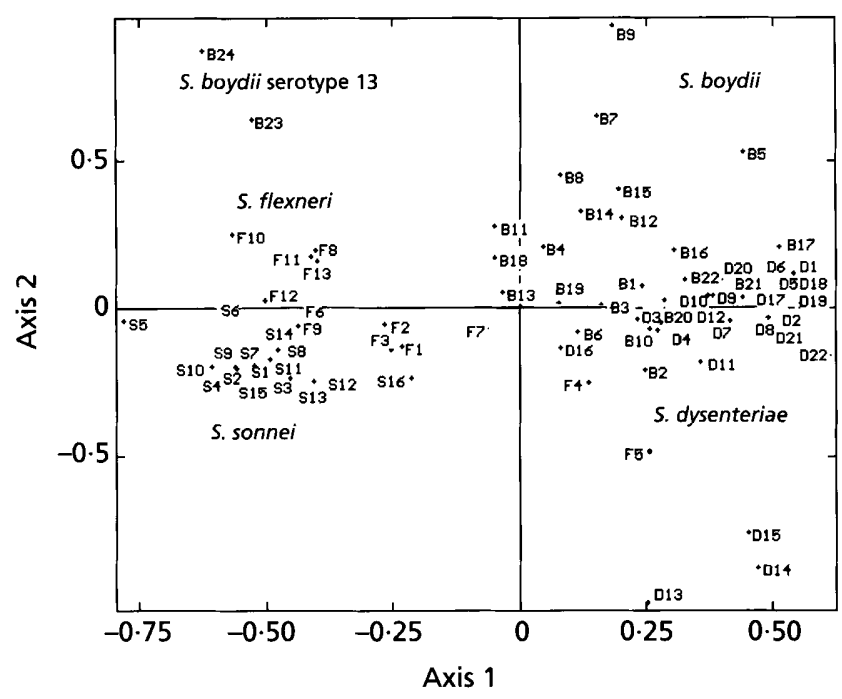

Fig. 2. Correspondence analysis of the 75 Shigella strains using RFLP analysis of the rRNA genes. Projection of the strains, numbered as in Table 1 , onto the plane F1/F2. For clarity, when several strains are projected onto the same point, only one is indicated.

projected into the area of group B1. S. sonnei, S. flexneri and the other $S$. dysenteriae strains were mostly projected into the area of phylogenetic group D. S. boydii strains were more widely distributed within these two ECOR areas. Eight of the 13 EIEC strains studied belonged to group B1, 4 to group A and 1 to group B2.

\section{DISCUSSION}

As with previous studies based on biochemical and serological characters (Dodd \& Jones, 1982) and electrophoretic polymorphism of esterases (Goullet, 1980; Goullet \& Picard, 1987), clusters of Shigella were distinguished by ribotyping (Figs 2,3). Thus, S. sonnei and $S$. flexneri were clearly distinguished from $S$. boydii and $S$. dysenteriae, whereas the distinction between $S$. boydii and S. dysenteriae was less clear (Fig. 2). The strains of $S$. boydii serotype 13 , which belong to a distinct DNA hybridization group (Brenner et al., 1982), were clearly distinguished from the other Shigella strains. Our rDNA RFLP data did not demonstrate the close taxonomic relationship between $S$. flexneri serotype 6 strains and $S$. boydii strains previously shown on the basis of several characters (Timakov et al., 1972; Dodd \& Jones, 1982; Goullet et al., 1983).

Ribotyping was highly discriminatory in the Shigella subspecies as 17 ribotypes were identified in $S$. dysenteriae, 12 in S. flexneri, 23 in S. boydii and 12 in S. sonnei. Serotyping (Orskov et al., 1977), biotyping (Marranzano et al., 1985) and isoenzyme analysis (Ochman et al., 1983) suggest that S. sonnei is genetically homogeneous. Our study is consistent with previous work showing that ribotyping can discriminate between S. sonnei clones (Karaolis et al., 1994). RAPD analysis of
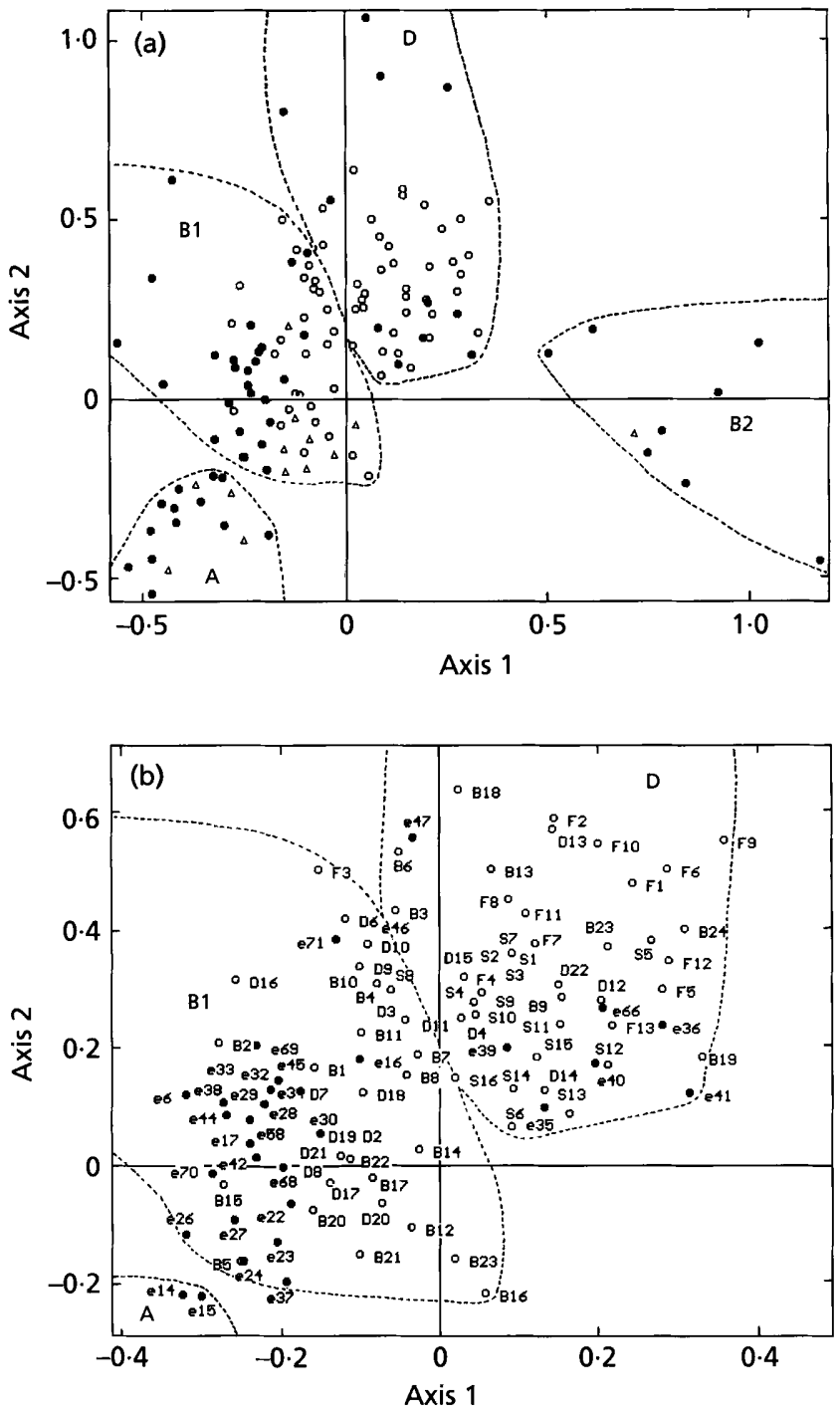

Fig. 3. Correspondence analysis of the 72 ECOR strains with the 75 Shigella and 13 EIEC strains treated as supplementary observations, using RFLP analysis of rRNA gene data. (a) The 72 ECOR strains ( $)$, the 13 EIEC strains $(\triangle)$ and the 75 Shigella strains $(O)$ are projected onto the plane $F 1 / F 2$. The phylogenetic groups of ECOR strains, A, B1, B2 and D (Herzer et al., 1990), are indicated by dotted lines. (b) Enlargement of the area of groups B1 and D. The Shigella strains are numbered as in Table 1. e, ECOR.

the 75 Shigella strains using the $18 \delta$ and $338 \delta$ primers (Desjardins et al., 1995) was less able than ribotyping to discriminate the four taxospecies (data not shown).

Previous studies have shown sufficient similarity between E. coli and Shigella to place both in the same species (Brenner et al., 1972, 1973; Goullet, 1980; Hartl \& Dykhuizen, 1984; Ochman et al., 1983; Whittam et al., 1983). The correspondence analysis comparing ECOR ribotypes and Shigella ribotypes supports this (Fig. 3). However, Shigella clones were more closely related to certain phylogenetic groups of the ECOR collection as they were unambiguously projected within the $\mathrm{B} 1$ and $\mathrm{D}$ groups even though some strains were 
projected within the B1 group area bordering the A group area. Moreover, S. sonnei, S. flexneri and most $S$. dysenteriae strains were closely related to group $\mathrm{D}$, whereas $S$. dysenteriae serotype 1 strains were closely related to group B1 and $S$. boydii strains were widely distributed among the B1 and D groups. The Shigella strains were unrelated to group A. There have been several studies of the relationship between a limited sample of Shigella isolates and E. coli strains. These studies have produced conflicting results. MLEE analysis was used to classify most Shigella electrophoretic types to E. coli group II (corresponding to phylogenetic groups D and B1 of Herzer et al., 1990) (Whittam et al., 1983; Ochman et al., 1983; Ochman \& Selander, 1984). Pupo et al. (1997) used the same technique to group most Shigella strains in a single cluster in phylogenetic group A, with $S$. flexneri serotype 2 and 4 strains in group D. However, the same authors showed that $m d h$ sequencing groups all Shigella strains except $S$. sonnei within the E. coli B1 group strains. Such differences may be due to a higher rate of recombination in Shigella than in E. coli strains (Desjardins et al., 1995; Guttman, 1997) or to convergent evolution resulting from selective pressure linked to their strict human intestinal biotype (Maynard Smith, 1996). Overall, the data support the notion put forward by Goullet \& Picard (1987) in a study of esterase electrophoretic polymorphism that there was no single primordial Shigella species and Shigella strains are derived from different ancestral strains of E. coli.

The Shigella clones were found to be distantly related to the B2 phylogenetic group. This is consistent with their virulence in humans. Thus, Shigella cause bacillary dysentery whereas phylogenetic group B2 consists of highly pathogenic strains, frequently implicated in extraintestinal infections and rarely isolated from the intestinal microflora (Goullet \& Picard, 1986a, b; Bingen et al., 1998). In contrast, despite having comparable virulence to Shigella and a homologous virulence plasmid in common (Ménard et al., 1996), the EIEC were found to belong to three phylogenetic groups of $E$. coli, consistent with the results of Pupo et al. (1997). Most strains were closely related to group B1, four strains belonged to group A and one to group B2. The proportion of EIEC belonging to the B2 group was similar to the proportion of $E$. coli strains belonging to the phylogenetic B2 group in the normal intestinal microflora of healthy individuals (Goullet \& Picard, 1986b).

It has been suggested that Shigella plasmid virulence genes were acquired from another genus, based on the fact that the $\mathrm{A}+\mathrm{T}$ content of the plasmid genes $(70-73 \%)$ is higher than that of the chromosomal genes $(50 \%)$ (Hale, 1991). Endonuclease digestion and Southern hybridization showed that the virulence plasmids of Shigella and EIEC are essentially homologous but have different endonuclease patterns (Sansonetti et al., 1983). This suggests that these may have been a common ancestor molecule which has been subject to evolution. Phylogenetic plasmid analysis should help to determine how the virulence plasmid was acquired by Shigella and EIEC strains.

\section{ACKNOWLEDGEMENTS}

We thank Philippe J. Sansonetti and Philippe Bouvet for providing the EIEC strains, and Jacques Elion for constant encouragement.

\section{REFERENCES}

Bingen, E., Denamur, E., Lambert-Zechovsky, N., Aujard, Y., Brahimi, N., Geslin, P. \& Elion, J. (1992). Mother-to-infant vertical transmission and cross-colonization of Streptococcus pyogenes confirmed by DNA restriction fragment length polymorphism analysis. J Infect Dis 165, 147-150.

Bingen, E., Picard, B., Brahimi, N., Mathy, S., Desjardins, P., Elion, J. \& Denamur, E. (1998). Phylogenetic analysis of Escherichia coli strains causing neonatal meningitis suggets horizontal gene transfer from a predominant pool of highly virulent B2 group strains. J Infect Dis 177, 642-650.

Bohnert, M. G., d'Hauteville, H. M. \& Sansonetti, P. J. (1988). Detection of enteric pathotypes of Escherichia coli by hybridization using six DNA probes. Ann Inst Pasteur Microbiol 139, 189-202.

Brenner, D.-J., Fanning, G. R., Skerman, F. J. \& Falko, W. S. (1972). Polynucleotide sequence divergence among strains of Escherichia coli and closely related organisms. J Bacteriol 109, 953-965.

Brenner, D. J., Fanning, G. R., Miklos, G. V. \& Steigerwalt, A. G. (1973). Polynucleotide sequence relatedness among Shigella species. Int J Syst Bacteriol 23, 1-7.

Brenner, D. J., Steigerwalt, A. G., Gail Wathen, H., Gross, R. J. \& Rowe, B. (1982). Confirmation of aerogenic strains of Shigella boydii 13 and further study of Shigella serotypes by DNA relatedness. J Clin Microbiol 16, 432-436.

Desjardins, P., Picard, B., Kaltenböck, B., Elion, J. \& Denamur, E. (1995). Sex in Escherichia coli does not disrupt the clonal structure of the population: evidence from random amplified polymorphic DNA and restriction-fragment-length polymorphism. J Mol Evol 40, 440-448.

Dodd, C. E. R. \& Jones, D. (1982). A numerical taxonomic study of the genus Shigella. J Gen Microbiol 128, 1933-1957.

Goullet, Ph. (1980). Esterase electrophoretic pattern relatedness between Shigella species and Escherichia coli. J Gen Microbiol 117, 493-500.

Goullet, Ph. \& Picard, B. (1986a). Comparative esterase electrophoretic polymorphism of Escherichia coli isolates obtained from animal and human sources. J Gen Microbiol 132, 1843-1851.

Goullet, Ph. \& Picard, B. (1986b). Highly pathogenic strains of Escherichia coli revealed by the distinct electrophoretic patterns of carboxylesterase B. J Gen Microbiol 132, 1853-1858.

Goullet, Ph. \& Picard, B. (1987). Differentiation of Shigella by esterase electrophoretic polymorphism. J Gen Microbiol 133, 1005-1017.

Goullet, Ph., Picard, B. \& Toucas, M. (1983). Différenciation du sérotype 6 des sérotypes 1 and 5 de Shigella flexneri par électrophorèse et focalisation isoélectrique de leurs estérases. Ann Microbiol 134B, 269-276.

Greenacre, M. J., (1984). Theory and applications of correspondences. London: Academic Press.

Guttman, D. S. (1997). Recombination and clonality in natural populations of Escherichia coli. Trends Ecol Evol 12, 16-22. 
Hale, T. L. (1991). Genetic basis of virulence in Shigella species. Microbiol Rev 55, 206-224.

HartI, D. L. \& Dykhuizen, D. E. (1984). The population genetics of Escherichia coli. Annu Rev Genet 18, 31-68.

Herzer, P. J., Inouye, S., Inouye, M. \& Whittam, T. S. (1990). Phylogenetic distribution of branched RNA-linked multicopy single-stranded DNA among natural isolates of Escherichia coli. $J$ Bacteriol 172, 6175-6181.

Johnson, R., Colwell, R. R., Sakazaki, R. \& Tamura, K. (1975). Numerical taxonomy studies of the Enterobacteriaceae. Int J Syst Bacteriol 25, 12-37.

Karaolis, D. K. R., Lan, R. \& Reeves, P. R. (1994). Sequence variation in Shigella sonnei (Sonnei), a pathogenic clone of Escherichia coli, over four continents and 41 years. J Clin Microbiol 32, 796-802.

Lebart, L., Morineau, A. \& Warwick, K. M. (1984). Multivariate descriptive analysis and related techniques for large matrices. New York: Wiley Interscience.

Marranzano, M., Giammanco, G., d'Hauteville, H. \& Sansonetti, P. (1985). Epidemiological markers of Shigella sonnei infections: Rplasmid fingerprint, phage-typing and biotyping. Ann Inst Pasteur Microbiol 136, 339-345.

Maynard Smith, J. (1996). Population genetics: an introduction. In Escherichia coli and Salmonella: Cellular and Molecular Biology, 2nd edn, vol. II, pp. 2685-2690. Edited by F. C. Neidhardt and others. Washington, DC: American Society for Microbiology.

Ménard, R., Dehio, C. \& Sansonetti, P. J. (1996). Bacterial entry into epithelial cells : the paradigm of Shigella. Trends Microbiol 4, 220-226.

Ochman, H. \& Selander, R. K. (1984). Standard reference strains of Escherichia coli from natural populations. J Bacteriol 157, 690-693.

Ochman, H., Whittam, T. S., Caugant, D. A. \& Selander, R. K. (1983). Enzyme polymorphism and genetic population structure in Escherichia coli and Shigella. J Gen Microbiol 129, 2715-2726.

Orskov, I., Orskov, F., Jann, B. \& Jann, K. (1977). Serology, chemistry and genetics of $\mathrm{O}$ and $\mathrm{K}$ antigens of Escherichia coli. Bacteriol Rev 41, 667-710.
Picard-Pasquier, N., Ouaghed, M., Picard, B., Goullet, Ph. \& Krishnamoorthy, R. (1989). A simple, sensitive method of analyzing bacterial ribosomal DNA polymorphism. Electrophoresis 10, 186-189.

Pupo, G. M., Karaolis, R., Lan, R. \& Reeves, P. R. (1997). Evolutionary relationship among pathogenic and non pathogenic Escherichia coli strains inferred from multilocus enzyme electrophoresis and mdh sequence studies. Infect Immun 65, 2685-2692.

Sansonetti, P. J., d'Hauteville, H., Ecobichon, C. \& Poucel, C. (1983). Molecular comparison of virulence plasmids in Shigella and enteroinvasive Escherichia coli. Ann Microbiol 134A, 295-318.

Selander, R. K. \& Levin, B. R. (1980). Genetic diversity and structure in Escherichia coli populations. Science 210, 545-547.

Sereny, B. (1955). Experimental Shigella keratoconjunctivitis. A preliminary report. Acta Microbiol Acad Sci Hung 2, 293-296.

Southern, E. M. (1975). Detection of specific sequences among DNA fragments separated by gel electrophoresis. J Mol Biol 98, 503-517.

Szturm-Rubinstein, S. (1964). Répartition géographique des biotypes et lysotypes de 743 souches de S. sonnei. Ann Inst Pasteur 106, 114-122.

Tenehaus, M. \& Young, F. W. (1985). An analysis and synthesis of multiple correspondence analysis, optimal scaling, dual scaling, homogeneity analysis, and other methods for quantifying categorical multivariate data. Psychometrika 50, 91-119.

Timakov, V. D., Petrovskaya, V. G., Bondarenko, V. M. \& Khomenko, N. A. (1972). Genetic data concerning Shigella flexneri serotypes 5 and 6. Int J Syst Bacteriol 22, 149-154.

Veron, M. \& Le Minor, L. (1975). Nutrition and taxonomy of Enterobacteriaceae and related bacteria. II. General results and classification. Ann Microbiol 126B, 111-124.

Whittam, T. S., Ochman, H. \& Selander, R. K. (1983). Multilocus genetic structure in natural populations of Escherichia coli. Proc Natl Acad Sci USA 80, 1751-1755.

Received 1 December 1997; revised 6 May 1998; accepted 18 May 1998. 